\title{
Induction of chronic marginal periodontitis in an experimental sheep model; clinical, radiological and histological evaluation
}

\author{
ALEXANDRU BOGDAN-CĂTĂLIN ${ }^{1}$, MONICA POPA ${ }^{1}$, LIVIU OANA ${ }^{2}$, CARMEN GEORGIU ${ }^{3}$, FLAVIU \\ TABARAN ${ }^{4}$, ADRIAN MACRI ${ }^{5}$, PURDOIU ROBERT $^{6}$, DAN ISTRATE ${ }^{7}$, GABRIELA DOGARU ${ }^{8}$, CAMELIA \\ LAZĂR ${ }^{3}$, BOSCA BIANCA $^{9}$, COSMIN PEȘTEAN $^{2}$, ANNE-MARIE CONSTANTIN ${ }^{9}$, ȘOVREA ALINA ${ }^{9}$
}

${ }^{1}$ Department of Hygiene, "Iuliu Haţieganu” University of Medicine and Pharmacy, Cluj-Napoca, Romania

${ }^{2}$ Department of Surgical Pathology, University of Agricultural Sciences and Veterinary Medicine, Cluj-Napoca, Romania ${ }^{3}$ Department of Pathological Anatomy, "Iuliu Hațieganu" University of Medicine and Pharmacy, Cluj-Napoca, Romania ${ }^{4}$ Department of Pathological Anatomy, University of Agricultural Sciences and Veterinary Medicine, Cluj-Napoca, Romania ${ }^{5}$ Department of Nutrition, University of Agricultural Sciences and Veterinary Medicine, Cluj-Napoca, Romania ${ }^{6}$ Department of Radiology, University of Agricultural Sciences and Veterinary Medicine, Cluj-Napoca, Romania ${ }^{7}$ Department of Scientific Research Methodology, "Iuliu Hațieganu” University of Medicine and Pharmacy, Cluj-Napoca, Romania ${ }^{8}$ Medical Rehabilitation Department, "Iuliu Hațieganu” University of Medicine and Pharmacy, Cluj-Napoca, Romania ${ }^{9}$ Department of Morphological Sciences, "Iuliu Hațieganu” University of Medicine and Pharmacy, Cluj-Napoca, Romania Addresses: "Iuliu Hațieganu" University of Medicine and Pharmacy, Victor Babeş Street no. 8, 400012, Cluj-Napoca, Romania University of Agricultural Sciences and Veterinary Medicine, Calea Mănăştur 3-5, 400372, Cluj-Napoca, Romania

\begin{abstract}
Objective. Many factors can induce the periodontal disease, including inadequate dietary intake, irritating factors of the marginal periodontium, and contamination with periodontal pathogens. Standardization of experimental animal models allows a rapid evaluation of therapeutic approaches.

Methods and results. The study included five sheep aged five years, receiving food intake with a high content of fats, oxalic and phytic acids. Local induction of periodontal disease consisted of a surgical procedure based on sectioning of superficial periodontal ligaments, instillation of periodontal exudate collected from human patients, and tooth neck ligation. Periodontitis was successfully induced in all the sheep included in the study. The comparisons between clinical and radiological indices (gingival recession, bleeding on probing, periodontal probing depth, demineralization of interdental septa) were highly statistically significant $(\mathrm{p}<<0.01)$. The histopathological aspects of periodontal disease were characterized: tooth bone resorption and destruction of periodontal ligaments, presence of bacterial plaque and calculus, inflammatory reaction with multifocal distribution, as well as gingival epithelial hyperplasia.

Conclusions. The natural increase in tooth mobility and predisposition of sheep to periodontal disease, induce a greater resemblance of this experimental model to the human condition and allows a more extensive study of therapeutic methods.
\end{abstract}

Keywords Chronic periodontitis, animal model, sheep, histopathology.

To cite this article: ALEXANDRU B-C, POPA M, OANA L, GEORGIU C, TABARAN F, MACRI A, PURDOIU R, ISTRATE D, DOGARU G, LAZĂR C, BOSCA B, PEȘTEAN C, CONSTANTIN A-M, ŞOVREA A. Induction of chronic marginal periodontitis in an experimental sheep model: clinical, radiological and histological evaluation. Rom Biotechnol Lett. 2020; 25(3): 1511-1525. DOI: 10.25083/rbl/25.3/1511.1525 


\section{Introduction}

Chronic periodontal disease (CPD) is a persistent immune inflammatory disease, highly prevalent in tooth-supporting tissues (MOMEN-HERAVI et al, 2017 [1]), extremely complex and multifactorial, with a difficult and controversial classification. CPD includes a wide range of diseases and can be localized or generalized; it can be further classified depending on its extension and severity, its association with risk factors and systemic diseases (HIGHFIELD, 2009 [2]). CPD predominantly affects adults (KINANE et al, 2017 [3]) and represents one of the main causes of edentation in patients aged over 40 years (NUVVULA et al, 2016 [4]). All the four main components of the periodontium (gingiva, periodontal ligament, alveolar bone and cementum) are affected by chronic periodontal disease, which finally leads to the destruction of tooth-supporting structures, as well as their loss (KINANE et al, 2017 [3]).

Why is the study of CPD important? So far, no direct causal relationship between CPD and chronic systemic diseases has been confirmed (MAWARDI et al, 2015 [5]); a number of studies have shown a two-way relationship between CPD and chronic systemic diseases. The relationship is clearer as the severity of periodontal disease is greater.

The virulence and the endotoxins of periodontal pathogens induce several systemic pathogenic mechanisms: endothelial dysfunction, oxidative stress, systemic inflammation, formation of foam cells, lipid accumulation, atherothrombosis, vascular remodeling (CHISTIAKOV et al, 2016 [6]). Chronic marginal periodontitis causes a systemic inflammatory response; associated with oxidative stress, it may increase the risk of developing atherosclerosis (MAWARDI et al, 2015 [5]), cardiovascular diseases (ischemic vascular diseases, hypertension, atrial fibrillation, heart failure) (CHISTIAKOV et al, 2016 [6]; (CARRIZALES-SEPÚLVEDA et al, 2018 [7]); (MARTIN-CABEZAS et al, 2016 [8]), diabetes mellitus (LAMSTER \& PAGAN, 2017 [9]). Also, CPD increases the risk of dyslipidemic profile and metabolic syndrome (MAWARDI et al, 2015 [5]), chronic respiratory diseases (CARDOSO et al, 2018 [10]), rheumatoid arthritis (HAJISHENGALLIS, 2015 [11]), systemic lupus erythematosus (SETE et al., 2016 [12]) or even adverse pregnancy outcomes (COBB et al, 2017 [13]). Data available from a number of meta-analyses have shown a positive association between the systemic hyperinflammatory state and the risk of several types of cancer: oral, pulmonary, pancreatic (MICHAUD et al, 2017 [14]), colorectal (MOMEN-HERAVI et al, 2017 [1]).

In humans, the slow spread, over years, of bacterial pathogens determines gingival inflammation towards the ligaments and bone (MOMEN-HERAVI et al, 2017 [1]). This process can last 10 or 15 years (RAMSEIER et al, 2017 [15]) and may trigger many other chronic diseases (PAPADOPOLUS et al, 2014 [16]). This slow immune process can be more rapidly reproduced in animal models, and the immune host response is complex, both local and systemic, and cannot be reproduced in vitro, which is the main argument to use experimental models (OZ \& PULEO, 2011 [17]). Furthermore, genetic alterations in animals also allow to identify the specific components of the immune response (GRAVES et al, 2012 [18]); (PAPADOPOULOS et al, 2014 [16]). Experiments on animals have facilitated detecting the key mediators involved in the initiation, progression and outcome of the disease, which control host response modulation, tissue homeostasis restoration and the improvement of tissue resistance to new or ongoing inflammation (KINANE et al, 2017 [3]).

Sheep have a predisposition to periodontitis, which is also termed "broken mouth", a disorder that according to microbiological studies involves both bacteria found in clinically manifest human periodontitis and bacteria located in the rumen, broken mouth in sheep generally manifesting acutely, which are associated with nutritional deficiencies (e.g., Porphyromonas gingivalis, Prevotella, Pseudomonas, etc.) (ANA C. BORSANELLI et al [70]); (MARCELLO P. RIGGIO et al [69]).

Also, sheep have bone anisotropy very similar to that found in humans (WANG Y et al [38]); (SOARES HB \& LAVINSKY L [39]), which has a major impact on periodontal status.

Regarding the implication of diet in the development of $\mathrm{CPD}$, an association between several dietary risk factors and the incidence and evolution of destructive periodontal disease has been demonstrated (OZ \& PULEO, 2011 [17]). Diet also has a local effect on the formation of plaque and development of periodontal inflammation. Inadequate intake of both macronutrients (carbohydrates, lipids, proteins) and micronutrients (vitamins) is a sensitive marker for the development of CPD (HUJOEL \& LINGSTRÖM, 2017 [19]).

Among micronutrients, vitamins B12, C and D are inversely correlated with the onset or progression of CPD (CHAPPLE et al, 2017 [20]). The reduction of plasma vitamin $\mathrm{C}$ concentrations increases the prevalence of periodontitis (VAN DER VELDEN et al, 2011 [21]). Vitamin B12 and vitamin $\mathrm{D}$ deficiency is also associated with periodontal disease progression (ZONG et al, 2016 [22]).

Low intake of minerals (magnesium, calcium, iron, zinc) and other antioxidants (vitamins A \& E, lycopene) is also correlated with higher levels of periodontal disease (DOMMISCH et al, 2018 [23]); (VAN DER VELDEN et al, 2011 [21]); (NAJEEB et al, 2016 [24]).

\section{Aim}

The aim of this study is to define the induction of chronic marginal periodontitis similar to human forms in an experimental sheep model, considering the natural evolution of the disease in sheep, which most frequently occurs in the acute form (broken mouth). We used as a working hypothesis the environmental factors and the local factors that are also commonly found in human disease, with a pathogenic role in the development of periodontal disease. Consequently, the following were considered as potential pathogenic factors: sedentariness, inadequate food intake and instillation for CPD induction of periodontal exudate collected from patients with chronic marginal periodontitis, followed by chronic irritation of the marginal periodontium, for a long time period.

\section{Material and Method}

The study was conducted based on the Ethics Committee approval no. 23 of 23.01.2015, issued by "Iuliu Hațieganu" University of Medicine and Pharmacy Cluj-Napoca in collaboration with the University of Agricultural Sciences and Veterinary Medicine Cluj-Napoca. The study included five sheep (Ovis aries, Romanian Turcana breed), aged five years, 
non-pregnant females (which presented no gestational processes after inclusion in the study), multiparous, with a weight ranging between $40-60 \mathrm{~kg}$, without cardiac diseases or other organic disorders.

In order to establish a correct diagnosis of the periodontal status corresponding to the species, a healthy 2-year-old non-pregnant adult female sheep was evaluated clinically and radiologically (control).

To avoid the suffering of the animals, they were sedated before any therapeutic or diagnostic procedure, according to the following protocol:

Anesthesia protocol for sheep: female, aged 5 years, multiparous, with a weight between $40-60 \mathrm{~kg}$, without cardiac diseases or other organic disorders.

Venous approach - the saphenous vein was catheterized with a 20G IV catheter.

Preanesthesia - Atropin $0.02 \mathrm{mg} / \mathrm{kg}$ subcutaneously to reduce hypersalivation, Diazepam $0.5 \mathrm{mg} / \mathrm{kg}$ intravenously.

Induction of anesthesia - Ketamine $5 \mathrm{mg} / \mathrm{kg}$ intravenously and Propofol intravenously with an effect ranging between $2-4 \mathrm{mg} / \mathrm{kg}$, intubation using a 5.5 or 6 ETT.

Maintenance of anesthesia - with 1.5-2\% Isoflurane in $100 \%$ oxygen (a Midmark Matrx VME2 device was used).

Monitoring of vital functions by: ECG, capnography, pulse oximetry (a Drager Infinity Delta device was used).

Fluids: Ringer's lactate solution $5 \mathrm{ml} / \mathrm{kg} / \mathrm{h}$ were administered.

Analgesis - was performed with Flunixin $1 \mathrm{mg} / \mathrm{kg} \mathrm{SC}$ at 24 hours

The first stage of the study included analgosedation followed by:

\section{Radiological examination}

For radiological examination, a parallel technique for the mandibular incisors was adapted. The mandibular basilar bone was placed on the horizontal plane of the table, while the head was maintained in extension bilaterally by two stands that kept it in position. The X-ray beam penetrated at an angle of 90 degrees to the horizontal plane, above the nasal fossae. This technique generates the radiological image in front view and can only be performed under sedation (Figure 1).

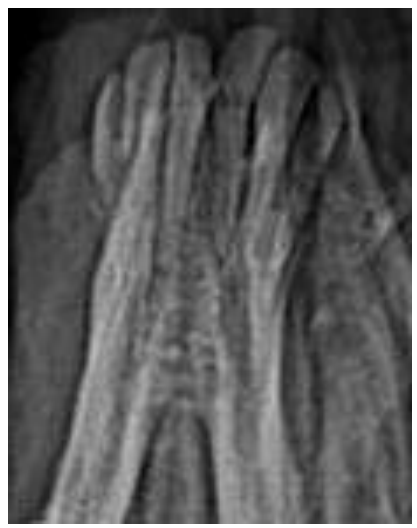

Figure 1. The radiological image obtained by the described technique allows the radiological examination of mandibular front teeth, especially the central incisors.

The radiological image represents a 2-year-old control sheep.

\section{Initial periodontometry strictly performed in the mandibular front teeth}

To assess tooth mobility and the probing depth, three types of measurements and tests of the tooth mobility directions were carried out: axial, mesio-distal and vestibulo-oral.

Clinical evaluation included the assessment of periodontal probing depth, using an 11-mm long graded periodontal probe with a tip diameter of $0.5 \mathrm{~mm}$ (Figures 2,3) (TEOFIL LUNG \& MĂDĂLINA LAZĂR [25]), as well as tooth mobility, which was determined manually using a dental clamp and the graded periodontal probe. Six gingival sulcus points corresponding to the tooth surfaces were assessed by probing: mesio-vestibular, centro-vestibular, disto-vestibular, disto-lingual, centro-lingual and mesio-lingual.

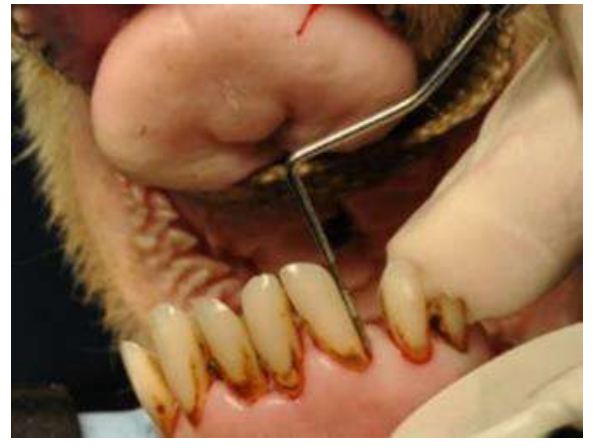

Fig. 2.

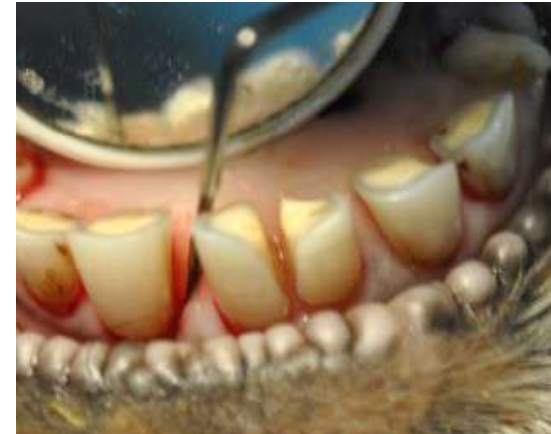

Fig. 3.

Figures 2 and 3 illustrate images during the initial periodontal probing depth measurement.

\section{Local intervention on the marginal perio- dontium}

Local intervention for induction of the disease consisted of: sectioning of superficial marginal periodontal ligaments (Figure 4), followed by instillation of periodontal exudate collected from human patients with chronic marginal periodontitis (Figure 5), continuing with tooth neck ligation with multifilament silk non-absorbable sutures placed as deep as possible into the gingival sulcus, to violate the biological desmodontal space (Figure 6). 


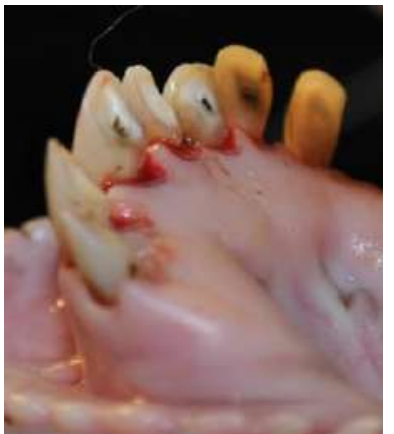

Figure 4. Image taken immediately after sectioning of the marginal periodontal ligaments.

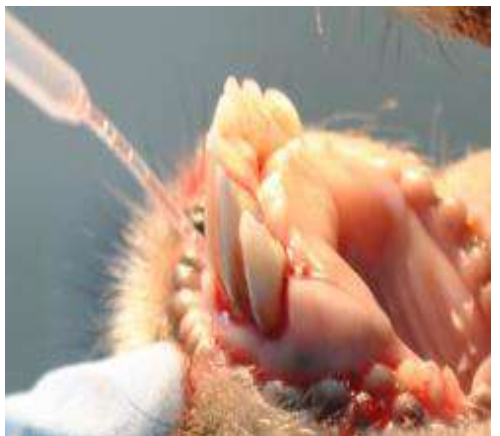

Figure 5. Instillation of periodontal exudate collected from human patients with chronic marginal periodontitis.

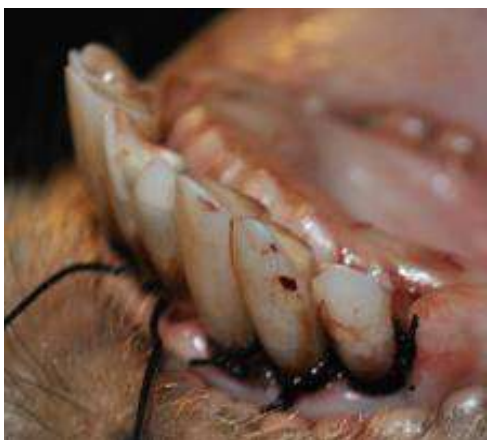

Figure 6. Tooth neck ligation

\section{Diet and environmental conditions}

Diet was initiated immediately after local treatment Over a period of 10 months, the ration of each sheep included in the study was calculated for a weight ranging between $40-60 \mathrm{~kg}$ and consisted of: $1 \mathrm{~kg}$ hay, $100 \mathrm{~g}$ zea mays, $200 \mathrm{~g}$ bone flour, $150 \mathrm{~g}$ rumex acetosa mixed with rhubarb (with petiole), as a dry mixture (BODEA AND ENĂCHESCU, 1984 [26]), administered in two portions. This ration was established taking into consideration the dynamic structure of ruminal bacteria, which is different at different times (LI et al, 2014 [27]), as well as hydroxyapatite absorption (NIEUW AMERONGEN et al, 1988 [28]), which in the presence of phytates can decrease up to $100 \%$ in the case of sheep. The housing conditions were optimal in terms of temperature, humidity and light sources, while the sheep were permanently confined in pens that did not allow extensive movements. months.

The sheep experienced no weight loss during the ten

\section{Statistical analysis}

To test the differences between the pre- and postinduction mean values of the six measured periodontometric parameters (mesio-vestibular, centro-vestibular, disto-vestibular, disto-lingual, centro-lingual and mesiolingual), the $\mathrm{T}$ test for paired samples was used. The null hypotheses were rejected and the alternative hypotheses were accepted. The difference between the calculated means, graphically represented, was statistically significant, with a $\mathrm{p}$ value $<<0.01$.

To test the differences in the mean values of the tooth mobility indices (vestibulo-oral, mesio-distal and axial) between the control sheep and the sheep with induced chronic periodontitis, the $\mathrm{T}$ test for independent samples with unequal variables was used. For the equality of the previously tested variables, the $\mathrm{F}$ test was used.

After a period of 10 months, the animals were reexamined based on dental radiographs and post-induction periodontometry, and two of the five sheep were euthanized for histological evaluation.

Euthanasia was performed by injection of the medication into the saphenous vein, according to the following protocol: after previous sedation with Xylazine $0.1 \mathrm{mg} / \mathrm{kg}$ IV (Xylazin Bio 2\% Bioveta, Czechia), sodium pentobarbital $140 \mathrm{mg} / \mathrm{kg}$ IV (Euthasol Vet, Le Vet B.V., Netherlands) was administered.
The specimens for histological examination were collected by sectioning the chin with the entire front teeth group, in the same session, immediately after euthanasia.

\section{Histological examination}

The mandibular specimens were fixed in $10 \%$ formaldehyde.

Sagittal sections of the anterior mandible were cut. The mandibular sections were fixed in formaldehyde solutions for subsequent processing.

Processing by fixation, decalcification and paraffin embedding of the tissues was performed. Immediately after the tissues were sectioned, they were fixed in $10 \%$ neutral buffered formaldehyde solution to facilitate the access of the fixing solution (SILVA et al, 2011 [29]). Decalcification in $10 \%$ neutral EDTA buffer and nitric acid was performed (LIU et al, 2017 [30]), until flexibility by manual testing was obtained. The samples for histological examination were cut sagittally. The decalcified tissues were embedded in paraffin and cut manually at a thickness of $5 \mu \mathrm{m}$.

For hematoxylin-eosin staining (H\&E) of the decalcified sections, the slides were deparaffinized in xylene, rehydrated in a descending ethanol concentration and stained with hematoxylin for 20 minutes, washed, after eosin Y staining for 4 minutes. Subsequently, the slides were washed, dehydrated in ascending ethanol concentrations, then cleaned with xylene and mounted (FOSTER, 2012 [31]).

PAS staining evidences glycogen and glycated compounds. The sectioned tissues are first oxidized in periodic Schiff acid. The oxidative process results in the formation of aldehyde groups by cleavage of the carbon-carbon bond. Free hydroxyl groups should be present for oxidation. Oxidation is completed when the aldehyde stage is reached. Aldehyde groups are detected by Schiff reagent. A colorless, unstable dialdehyde compound is formed, which is subsequently transformed into the colored end product by restoration of the quinoid chromophoric group (BILGE FETTAHL OĞLU KARAMAN et al [32]).

Giemsa staining can be used to study the adhesion of pathogens to cells. It differentially stains human and bacterial cells purple and pink respectively (WOODS GL \& WALKER $\mathrm{DH}$ [33]). Giemsa solutions represent a mixture of polychrome methylene blue and eosin $\mathrm{Y}$ dissolved in methanol and glycerol (STEFANOVIĆ, D et al [34]). 
The slides are immersed in the Giemsa solution and the tris-maleic buffer, heated to $60^{\circ} \mathrm{C}$ in a microwave oven, stained for 10 minutes at room temperature. Differentiation is obtained with a $1 \%$ acetic acid solution in absolute ethanol, which also initiates dehydration, followed by cleaning (BUESA, RJ [35]).

Gram staining allows differentiating between Grampositive and Gram-negative bacteria based on differential staining with a crystal violet-iodine complex and safranin content. The cell walls of Gram-positive microorganisms maintain this complex after alcohol treatment and stain purple, while Gram-negative organisms stain pink after such a treatment (COICO R, 2005 [36]).

A crystal violet solution was applied to tissue sections for 5 minutes at room temperature, and the slides were briefly rinsed with tap water to remove excess crystal violet, followed by Gram iodine mordant, which was applied to the tissue sections for $2 \mathrm{~min}$ and was briefly washed with tap water. In order to remove any non-specific crystal violet staining, a decolorizing Gram solvent was applied to the slides for 30 seconds, then was rapidly washed with tap water until the water ran clear. The sections were then stained with Gram Safranin for $1 \mathrm{~min}$ and $40 \mathrm{~s}$, followed by dehydration through

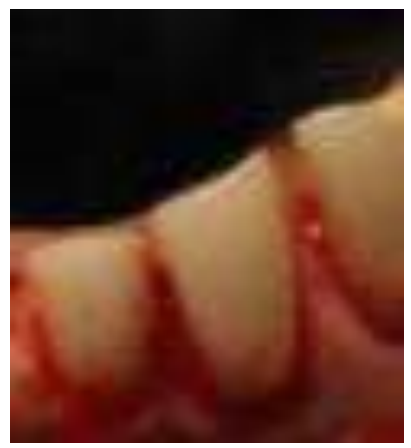

Fig. 7.

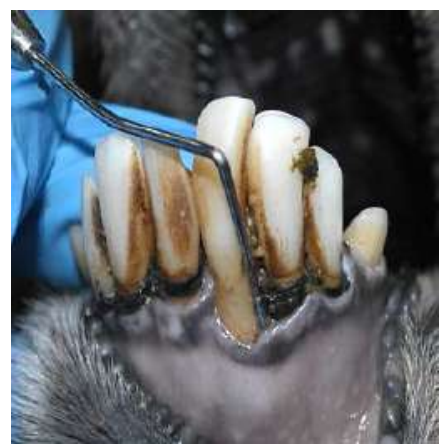

Fig. 9. a series of alcohols $(95-100 \%)$ to xylene and then coverslipped (BECERRA SC et al [37]).

The microscopic sections included bone structures with the inner and outer cortical bone, alveolar bone (the alveolar bone proper and the medullary alveolar bone), oral epithelium, sulcular epithelium, junctional epithelium, gingival sulcus, gingival corium, periodontal ligaments, desmodontium, as well as dental structures including: cementum, dentin, enamel, dental vasculo-nervous bundle. The images were examined and photographed with a Leica D-500 microscope.

\section{Results}

During the 10-month disease induction period, after initial evaluation and local surgery, followed by food ration administration and housing in a space that did not allow the animals to perform extensive movements, the following were observed: gingival recession, presence of bleeding on probing, differences in periodontal probing depth, as well as teeth exfoliation, without associated organic disorders. The animals were reexamined after a period of 10 months, under sedation (no additional examinations were performed during this time period) (Figures 7, 8, 9, 10).

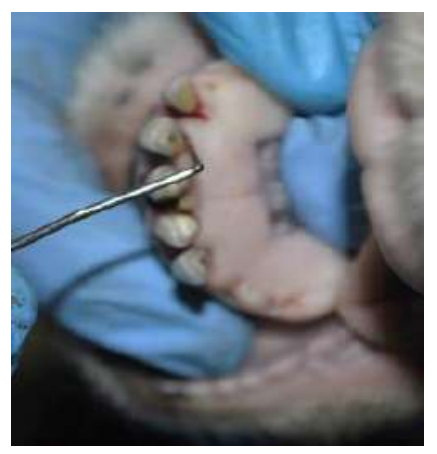

Fig. 8 .

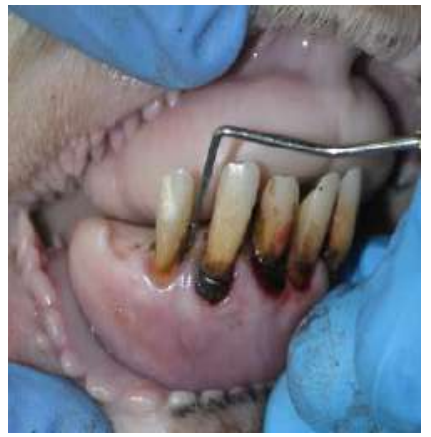

Fig. 10.

Figure 7 represents post-periodontometry Muhlemann bleeding gr. IV.

Figures 8, 9, 10 represent gingival recession, post-induction periodontometry, persistence of multifilament silk sutures in some teeth, presence of calculus deposits, gingival margin congestion.

The increase in periodontal probing depth as well as in tooth mobility was confirmed statistically. Major differences were observed in the six reference points, with highly statistically significant results.

1. Initial and post-induction mesio-vestibular (MV) evaluation evidenced a $\mathrm{p}<<0.01$ with a mean difference of
$4.39 \mathrm{~mm}(=6.18-1.79)$, representing the increase in postinduction values (Figure 11).

2. Initial and post-induction centro-vestibular evaluation evidenced a $\mathrm{p}<<0.01$ with a mean difference of $5.35 \mathrm{~mm}$ $(=5.88-0.53)$, representing the increase in post-induction values (Figure 12). 


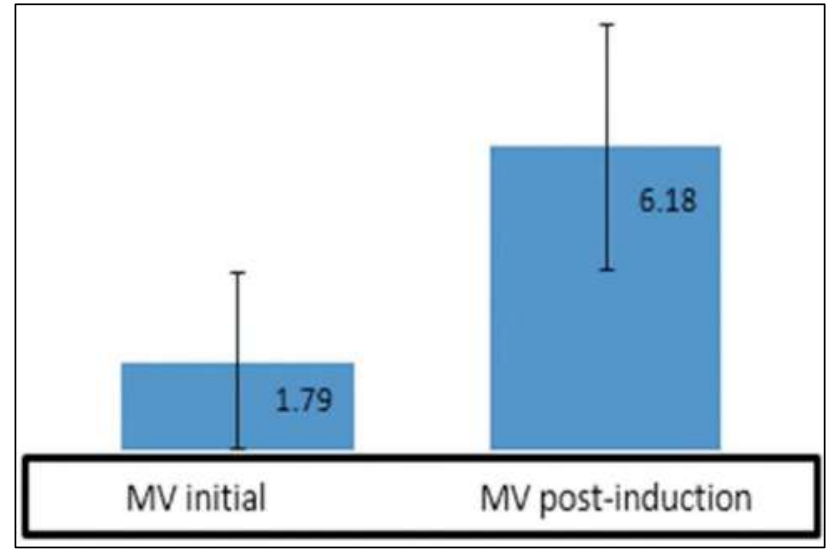

Figure 11. Initial and post-induction mesio-vestibular mean with the associated confidence intervals.

3. Initial and post-induction disto-vestibular evaluation evidenced a $\mathrm{p}<<0.01$ with a mean difference of $4 \mathrm{~mm}(=6.38$ $2.38)$, representing the increase in post-induction values (Figure 13).

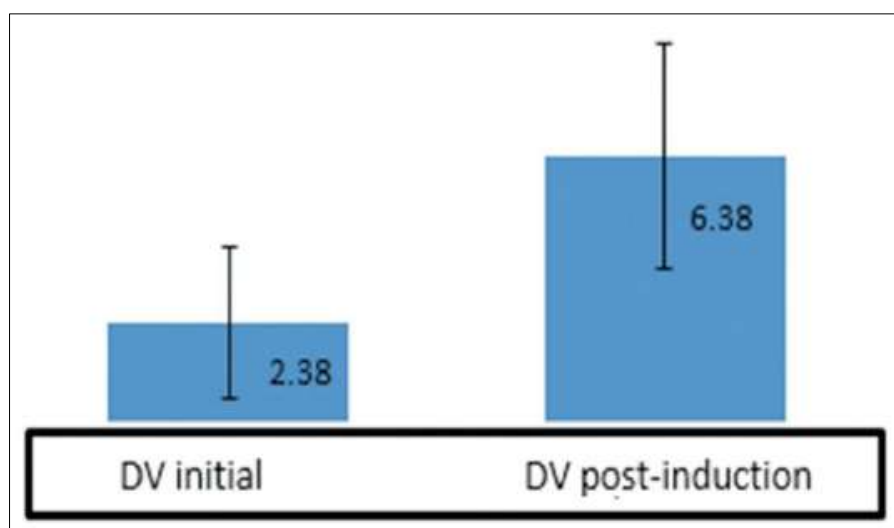

Figure 13. Initial and post-induction disto-vestibular mean with the associated confidence intervals.

5. Initial and post-induction centro-lingual (L) evaluation evidenced a $\mathrm{p}<<0.01$ with a mean difference of $4.15 \mathrm{~mm}(=7.97-3.82)$, representing the increase in postinduction values (Figure 15).

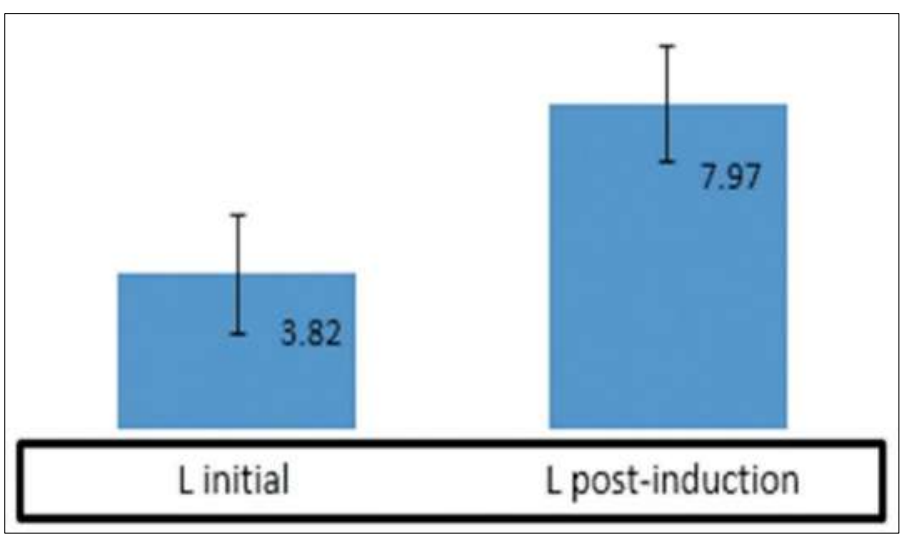

Figure 15. Initial and post-induction centro-lingual (L) mean with the associated confidence intervals.

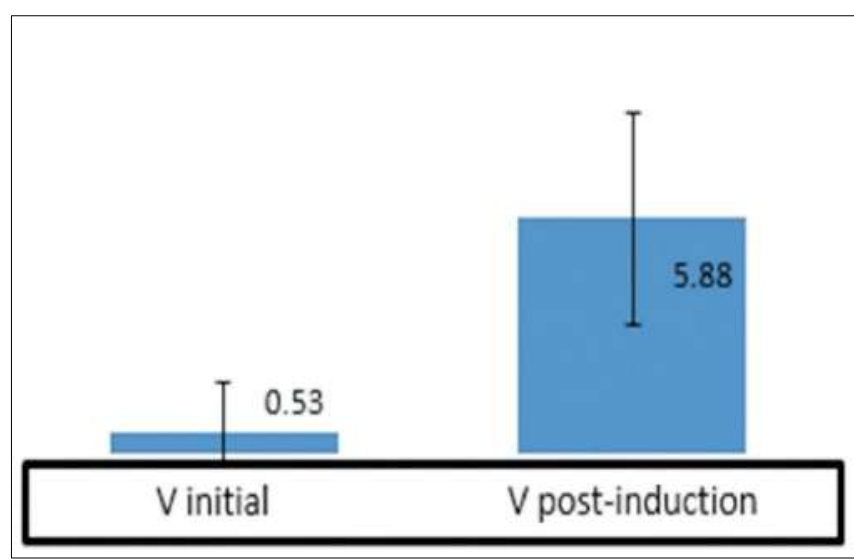

Figure 12. Initial and post-induction centro-vestibular (V) mean with the associated confidence intervals.

4. Initial and post-induction disto-lingual (DL) evaluation evidenced a $\mathrm{p}<<0.01$ with a mean difference of $3.5 \mathrm{~mm}(=7.44-3.94)$, which shows the increase in postinduction values (Figure 14).

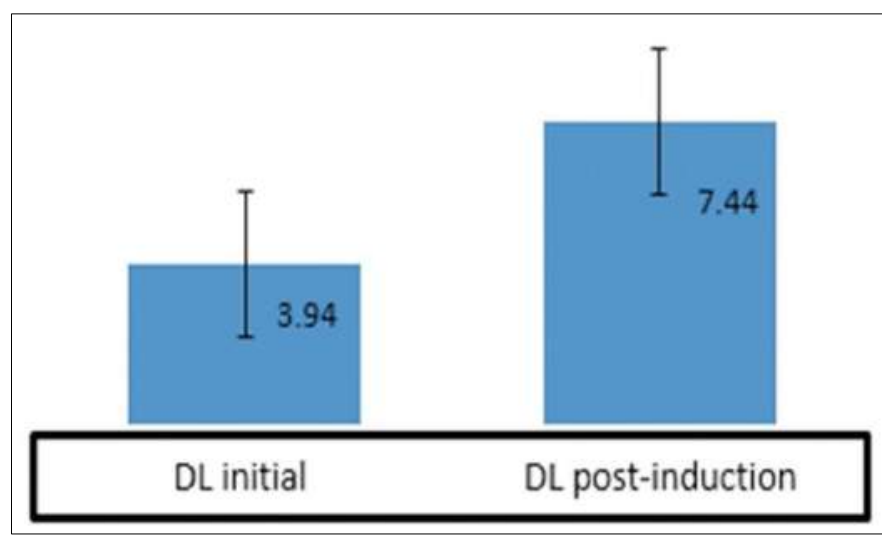

Figure 14. Initial and post-induction disto-lingual mean with the associated confidence intervals.

6. Initial and post-induction mesio-lingual (ML) evaluation evidenced a $\mathrm{p}<<0.01$ with a mean difference of $4.12 \mathrm{~mm}(=7.97-3.85)$, representing the increase in postinduction values (Figure 16).

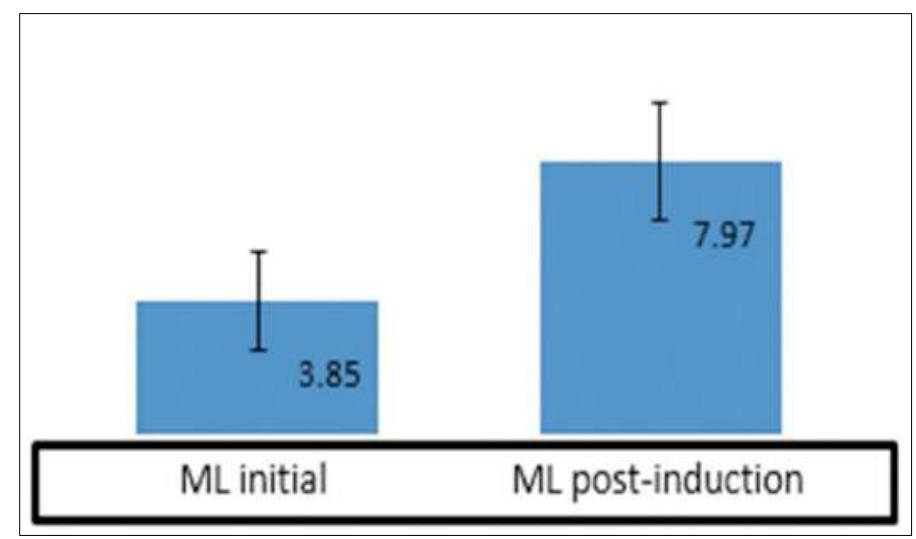

Figure 16. Initial and post-induction mesio-lingual (ML) mean with the associated confidence intervals. 
Regarding tooth mobility, for all three directions (axial, mesio-distal and vestibulo-oral), the results of the $\mathrm{F}$ test indicated a $\mathrm{p}<<0.01$, the result being highly statistically significant. The comparison was made between the control sheep and the sheep included in the study.

1. For mobility in vestibulo-oral (V-O) direction, a $\mathrm{p}<<0.01$ with a mean of $4.41 \mathrm{~mm}(=5.41-1)$ was obtained, representing the increase in mobility for the sheep included in the experiment (Figure 17).

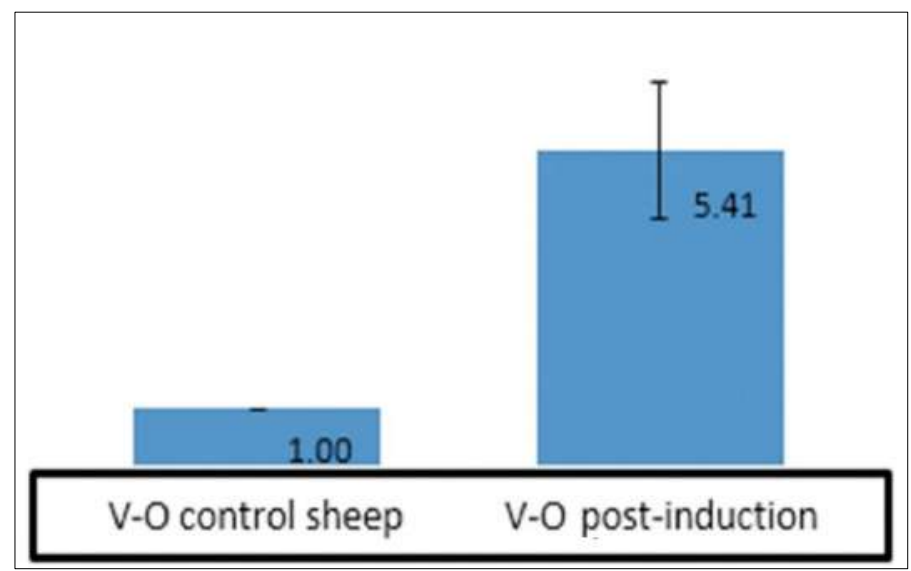

Figure 17. The reference vestibulo-oral mean between the control sheep and the sheep included in the study, with the associated confidence intervals.
2. For mobility in mesio-distal (M-D) direction, a $\mathrm{p}<<0.01$ with a mean of $4 \mathrm{~mm}(=4.35-0.35)$ was obtained, representing the increase in mobility for the sheep included in the experiment (Figure 18).

3. For mobility in axial direction, a $\mathrm{p}<<0.01$ with a mean of $2.43 \mathrm{~mm}(=2.99-0.56)$ was obtained, with an increase in mobility for the sheep included in the experiment (Figure 19).

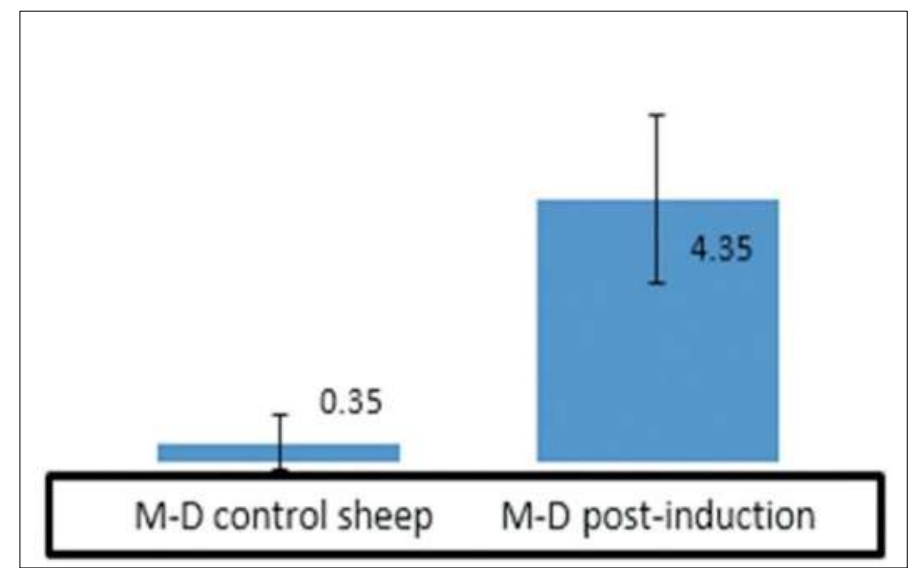

Figure 18. The reference mesio-distal mean between the control sheep and the sheep included in the study, with the associated confidence intervals.

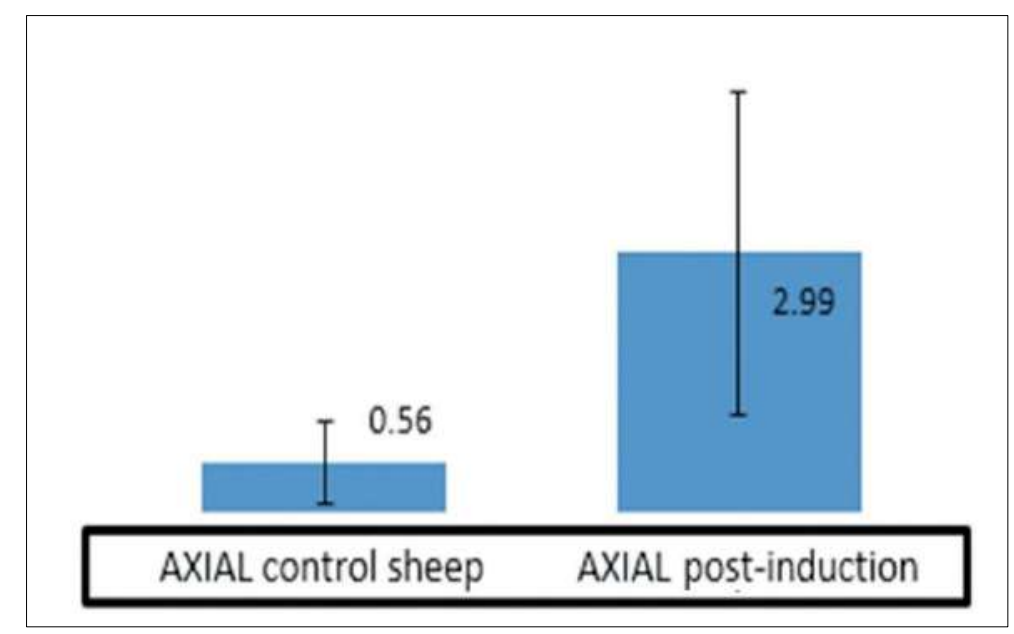

Figure 19. The reference axial mobility mean between the control sheep and the sheep included in the study, with the associated confidence intervals.

\section{Radiological results}

At the end of the experiment, demineralization of interdental septa and other few changes were observed, as shown in Figures 20 and 21, A - before disease induction and $\mathrm{B}-$ after disease induction. 


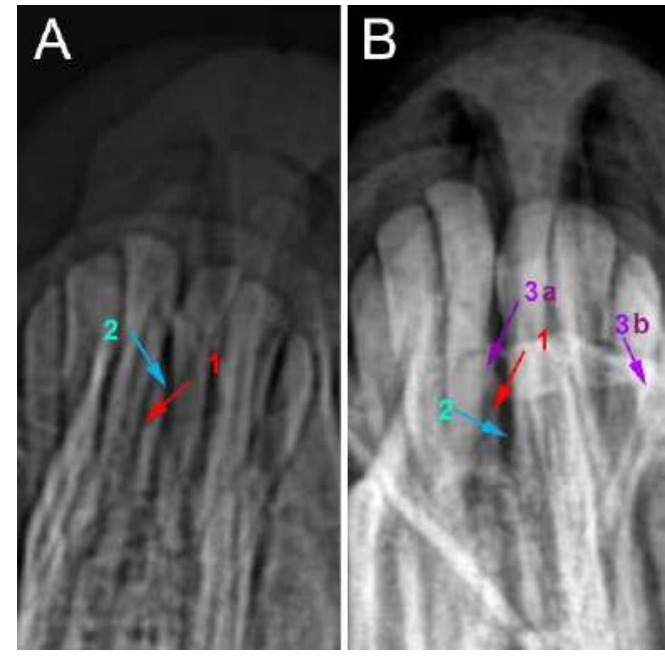

Figure 20. A1 - initial volume of the interdental septum; B1 - reduced volume of the interdental septum, with bone resorption, after disease induction; $\mathbf{A 2}$ - initial radiological dimensions of the desmodontal space; $\mathbf{B 2}$ - extensive and more profound desmodontal space; B3 - calculus deposits below the cementoenamel junction at the level of the central incisor (a) and in the cervical area of the third left incisor (b).
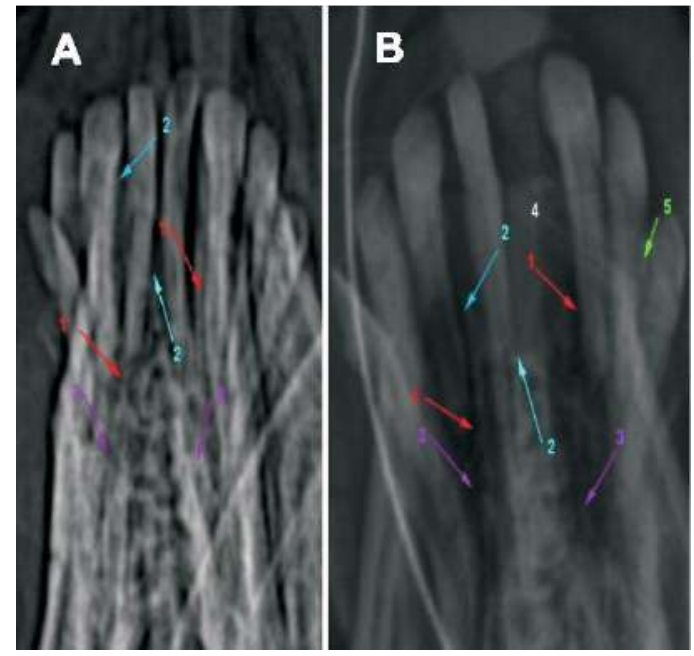

Figure 21. A1 - initial width of the desmodontal space; B1 - width of the desmodontal space after disease induction (larger); $\mathbf{A 2}$ - initial height of the interdental septum; B2 - interdental septum with bone resorption, after disease induction; A3 - initial intensity of bone mineralization; $\mathbf{B 3}$ - bone demineralization after disease induction; B4 - edentulous gap at the level of the exfoliated tooth; B5 - dental calculus in the cervical area.

tooth necks in the depth of the biological desmodontal space was observed, as well as the presence of calculus deposits (Figure 22).

In the samples used for histological examination, persistence of multifilament silk sutures at the level of the

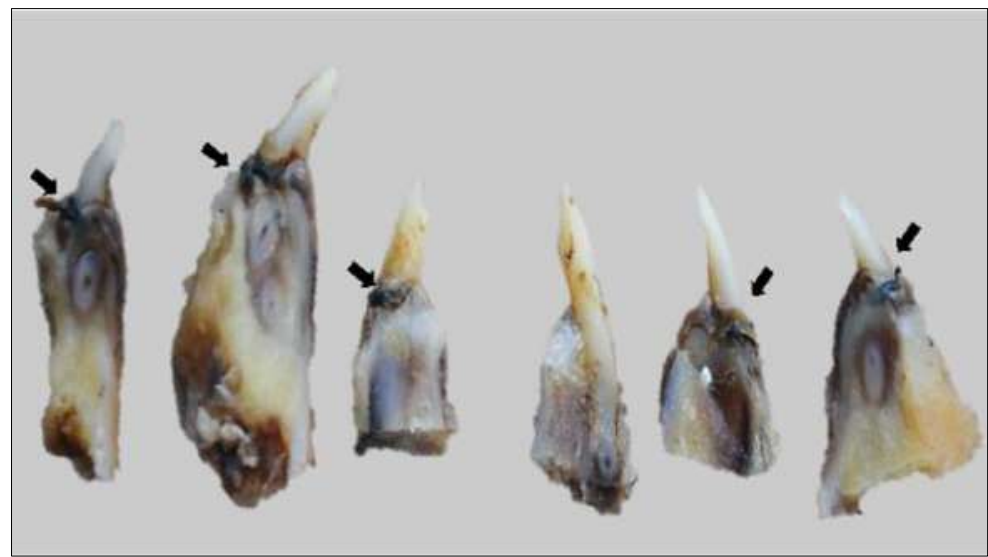

Figure 22. The sagittal section of the samples shows: persistence of sutures (arrows), calculus deposits (yellowish color).

\section{Microscopic images}

Periodontal destruction was evidenced in a number of histopathological changes: inflammatory reactions, bone resorption, cementum-dentin and dental resorption, destruction of periodontal ligaments, even the presence of bacterial species detected by special histological stains (Figures 23-29).

Hematoxylin-eosin staining showed inflammatory reactions and tissue destruction. PAS, Giemsa and Gram staining evidenced bacterial colonies. 


\section{Hematoxylin-eosin staining}

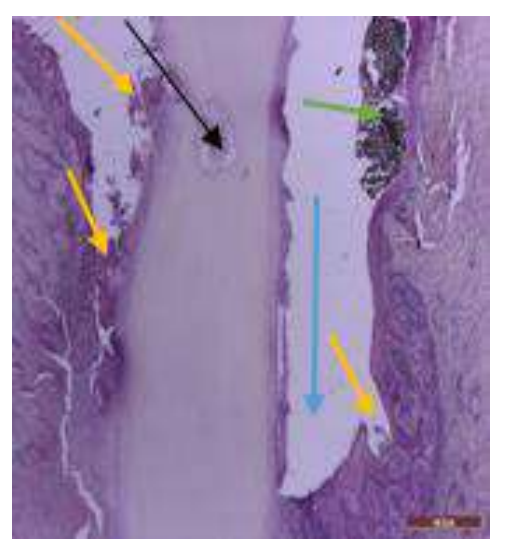

Figure 23. Dental bone resorption; presence of calculus (yellow arrow) and multifilament silk sutures (green arrow), ligament resorption + deep periodontal pocket (lingual surface) (blue arrow), calculus deposits enclosed in soft tissue (vestibular and lingual surfaces) (yellow arrow), tooth neck caries with retrograde evolution (black arrow).

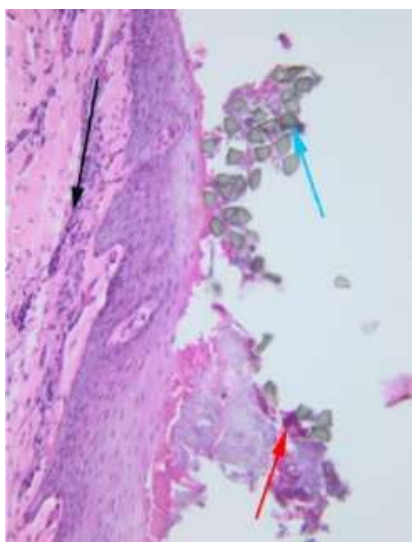

Figure 25. Calculus (red arrow) adherent to multifilament silk sutures (blue arrow), in contact with soft tissues that show inflammatory reaction (black arrow).

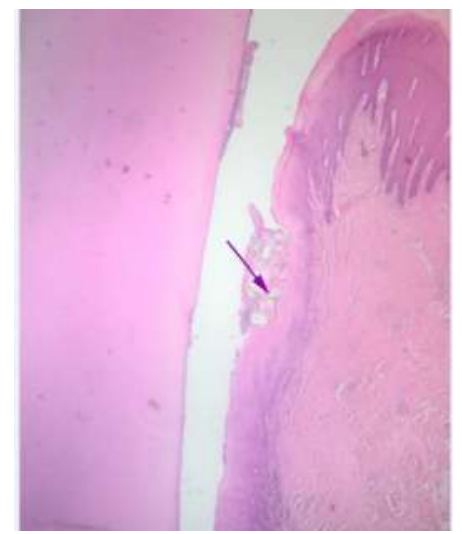

Figure 24. Calculus enclosed in soft tissue (on the lingual surface) (purple arrow).

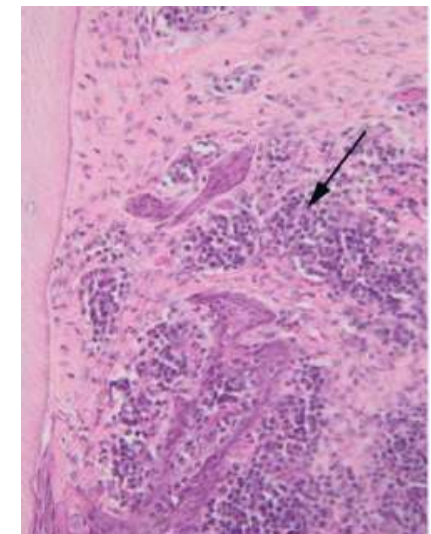

Figure 27. Extensive lymphoplasmacytic inflammatory infiltrate with rare neutrophils, multifocal distribution (black arrow), situated at the site of transition between hyperplastic gingival epithelium and the tooth.

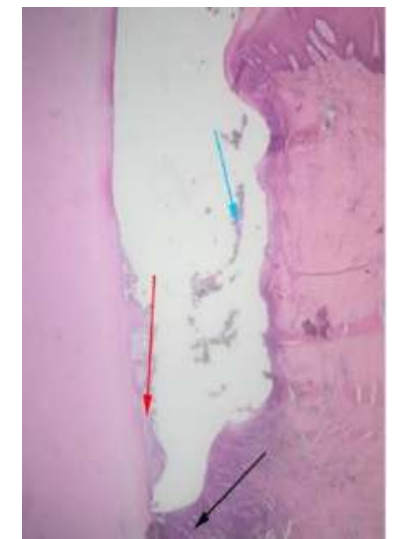

Figure 28. Destruction of the marginal periodontium, presence of calculus (red arrow) and bacterial plaque (blue arrow), destruction and inflammation of periodontal ligaments (black arrow).

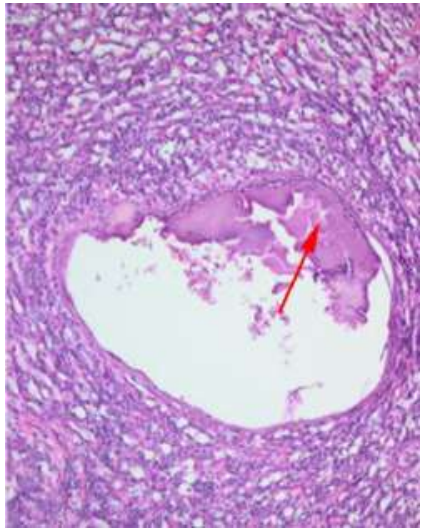

Figure 29. Calculus (red arrow) enclosed in soft tissues that show inflammatory reaction. 
Giemsa and PAS staining evidenced the presence of Actinomyces bacteria and cocci (Figures 30, 31, 32, 33).

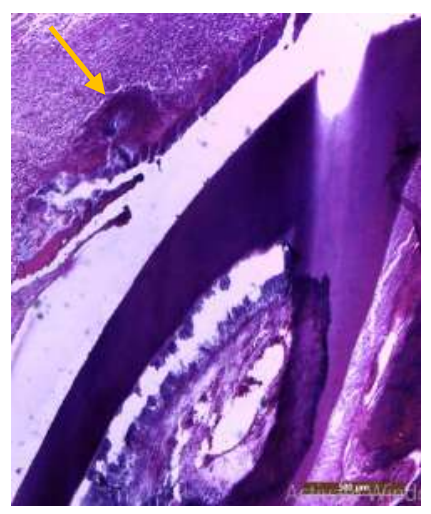

Figure 30. Actinomyces located in the inner epithelium of the periodontal pocket (yellow arrow) (PAS+ staining).

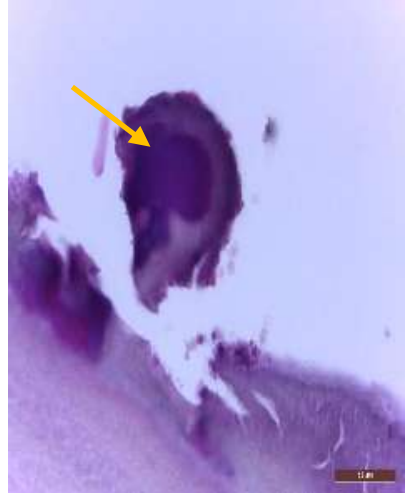

Figure 31. Actinomyces colony (PAS+ staining).

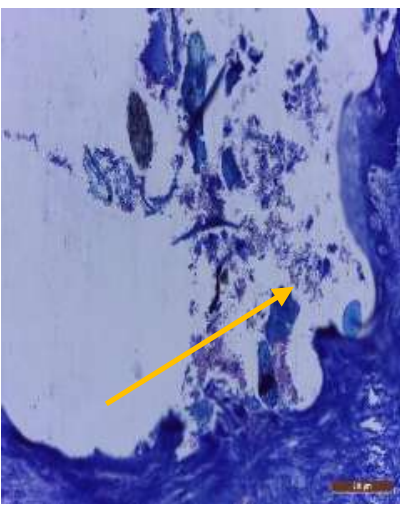

Figure 32. Cocci in the inner epithelium of the periodontal pocket (Giemsa staining).

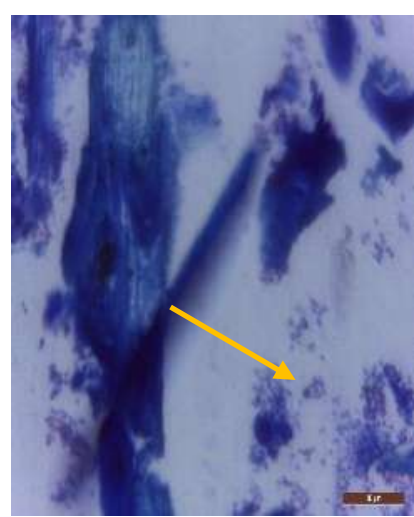

Figure 33. Cocci in the periodontal pockets (Giemsa staining).

Gram staining evidenced Gram-positive bacteria stained in blue (Figures 34, 35, 36, 37).

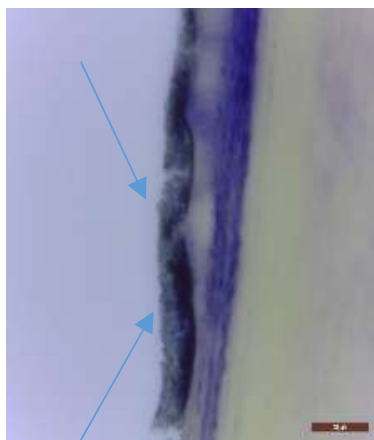

Fig. 34.

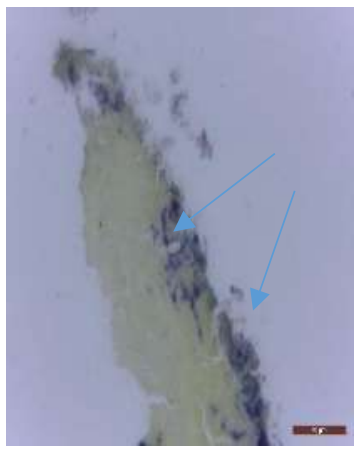

Fig. 35.

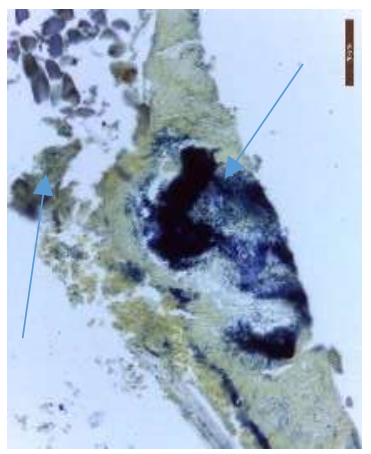

Fig. 36.

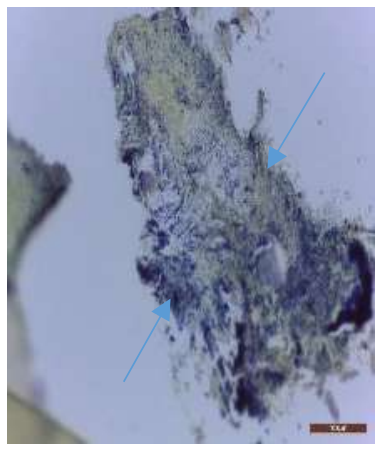

Fig. 37.

Figures 34, 35, 36, 37. Gram staining evidenced Gram-positive bacteria in the bacterial plaque found deep in the periodontal pockets.

\section{Discussions}

It was decided to initiate this study on sheep because under specific environmental conditions they acquire periodontal disease, generally in the acute form (broken mouth); in addition, bone anisotropy in sheep is very similar to that found in humans (WANG Y et al [38]); (SOARES HB et al [39]). Also, studies confirm the presence of bacterial species common to both sheep and humans under periodontal disease conditions (ANA C. BORSANELLI et al [70]).

The presence of Actinomyces bacteria, even if detected only by histological exams, confirms the fact that these can occur in chronic periodontitis forms as well.

Clinical measurements in CPD, such as periodontal pocket depth, tooth mobility and bleeding on probing, are essential for the diagnosis of this disease. These measurements have not yet been prevailed over by the efforts made to detect biomarkers in the gingival crevicular fluid (KINANE et al, 2017 [3]).

Regarding periodontal pocket depth, the statistically significant differences $(p<<0.01)$ between the mean values of the indicators evaluated by periodontometry for the six measured sites illustrated the success of this experimental model. The increase in the probing depth after 10 months from local surgery (a period during which the animals were subjected to an individualized lifestyle) was highly significant, which is why this model is suitable for further studies on therapeutic procedures.

A probing depth $\geq 5 \mathrm{~mm}$ and the number of sites with gingival recession were identified as predictors of risk for CPD (VAN DER VELDEN et al, 2006 [40]). In our study, we succeeded in reproducing probing depth values $\geq 6-7 \mathrm{~mm}$ (Figures 11, 13-16), which corresponds to the evolution of the chronic process and shows the usefulness of this model. The mesio-lingual (ML), centro-lingual (L) and disto-lingual 
(DL) sites showed good accuracy in estimating attachment loss and registered the highest probing depth values $(\geq 7 \mathrm{~mm})$. We took into consideration the results that do not overestimate chronic marginal periodontitis (CHU \& OUYANG, 2015 [41]) and are in accordance with the physiological particularities of sheep.

Chronic marginal periodontitis leads to progressive attachment loss followed by tooth loss (PAYNE et al, 2013 [42]). Since different degrees of severity of the inflammatory process result in different risks of periodontal attachment loss (SCHÄTZLE et al, 2004 [43]), it can be assumed that attempting to control and reduce inflammation can reduce the risk of tooth loss. A very important cause of the increase in inflammation is the development of dental plaque, especially in the subgingival area. In our 10-month study, we initiated several pathogenic mechanisms that contributed to the development of CPD: the instillation of pathogenic bacterial species (from the periodontal exudate collected from human patients with periodontal disease) favored the development of an oral bacterial biofilm and induced a chronic inflammatory process leading to the development of dental plaque and its calcification in the periodontal pockets (Figs. 23-26, 28, 29). Ions in the serum transudate resulting during the inflammatory process mainly favor bacterial plaque calcification in the subgingival area (KINANE et al, 2017 [3]), similarly to the plaque in our study. The presence of dental plaque concentrates the dental pathogens and increases their adherence to the tooth surface (JONES et al, 2011 [44]). The most frequent bacterial species identified in chronic periodontitis developed in our study were Actinomyces, important bacterial plaque forming organisms, which induced characteristic pathogenic changes (Figures 30, 31). This observation was also reported in human studies on chronic periodontitis (VIELKIND et al, 2015 [45]).

The evolution of the chronic periodontal process can be assessed by dental radiographs using the parallel technique (the development of a parallel technique for the current study described above); this can be used to easily measure the bone crest height and to evaluate the presence of factors contributing to plaque accumulation and calculus development (KOROSTOFF et al, 2016 [46]). In our clinical and radiological evaluation, we observed the presence of dental plaque and calculus deposits at the beginning of the study (Figures 2, 3); at the final radiological evaluation, subgingival calculus deposits were more markedly present, at the cementoenamel junction, with radiological visibility (Figure 15). Also, a decrease in height and demineralization of interdental septa were obvious.

In humans, the first molars are lost initially due to more extensive bacterial plaque deposits (JONES et al, 2011 [44]). The process is similar in sheep, with the difference that the initial presence of the dental plaque was detected in the mandibular front teeth, which is favored by the absence of antagonist teeth; in time, these aspects lead to the loss of those teeth. In our study, surgery forced the progression of chronic marginal periodontitis in a period of 10 months. Of the 7 mandibular incisors observed initially, 2 were lost $(28.57 \%)$

In this study, an adjuvant factor in the obtaining of a successful experimental model was dietary control. The high dietary intake of oxalic acid and phytic acid (found in rhubarb, rumex acetosa and zea mays), as well as animal fats induced a decrease in intestinal calcium absorption (ASLANI et al,
2011 [47]), by formation of non-resorbable compounds, along with a fatty diet that diminished salivary calcium absorption (NIEUW AMERONGEN et al, 1988 [28]), favoring the onset of the disease.

\section{Advantages of the experimental sheep model compared to other animal models}

Each animal model of CPD has its advantages and disadvantages. Each animal model shows similarities and dissimilarities to humans and allows the induction of clinical manifestations similar to those of human periodontitis (bleeding on probing, bone loss, deep periodontal pockets and tooth loss). Each animal model can test a component of the pathological process in periodontal disease. However, any dental study in animals involves a selection based on a different main investigation purpose: tissue regeneration, bone healing, inflammatory mediators, formation of calculus, implant studies.

Non-human primates are the most similar to man (dental structure, microflora), but their cost is extremely high, and periodontal disease occurs late in life and evolves over a long time period (OZ \& PULEO, 2011 [17]).

Rodents are the easiest to manipulate genetically in different genomes and microbial states, and are less expensive, but they are commonly used for the induction of acute periodontitis and for the study of the host-microbiome interaction (genetically manipulated rat strain for the study of specific immune interactions). At the same time, rodents have continuously growing teeth and a greater natural tooth regeneration capacity, they have a natural resistance to periodontitis and also have unique anatomical particularities of dental and periodontal tissues, which is why they do not reproduce human periodontitis progression (OZ \& PULEO, 2011 [17]); (MUSHEGYAN et al, 2015 [48]).

Hamsters have been used to illustrate the transmissibility of periodontal disease with plaque bacteria because they develop both the caries and extensive periodontal disease after bacterial inoculation. Nevertheless, in hamsters, the disadvantage is represented by inflammation, which is not the most important characteristic, as it is in humans (CHANDNA et al, 2011 [49]).

Rabbits present oral microorganisms similar to human periodontal flora (TYRRELL et al, 2002 [50]), and their use is less expensive. Pro-inflammatory and anti-inflammatory mechanisms in rabbits are similar to those found in humans (HASTURK et al, 2007 [51]). However, there are opinions according to which using rabbits is not adequate for the study of periodontal ligament regeneration (OORTGIESEN et al, 2010 [52]).

Dogs can develop periodontal disease similarly to humans both naturally and experimentally, but their use is also expensive, requires special care, and their teeth are also different from human dentition (OZ and PULEO, 2011 [17]). Dogs have a genetic breed predisposition to chronic diseases (such as periodontitis) and are physiologically closer to humans; consequently, they are more suitable for a comparative genomic approach of CPD (ALBUQUERQUE et al, 2012 [53]). In any case, they are animal models that are more widely used in the research of periodontitis compared to primates (DANNAN \& ALKATTAN, 2007 [54]).

Using pigs (particularly small breed pigs) in the study of CPD induced naturally or experimentally is adequate because 
they show many similarities to humans in terms of dental structure and physiology, and also have similar immunological and pathological mechanisms in the evolution of periodontitis (OZ \& PULEO, 2011 [17]); (WANG S et al, 2007 [55]). Another argument for the use of miniature pigs is gingivitis and periodontitis that occur naturally; consequently, there is an inflammatory process similar to that observed in human periodontal disease (LIU et al, 2008 [56]). However, the use of pigs is relatively expensive and involves growth-related problems. There are relatively few studies on pig models.

\section{Sheep as an experimental model of chronic marginal periodontitis}

Sheep have been used in many dental studies in a number of dental research areas: healing of periodontal wounds (DANESH-MEYER et al, 1997 [57]), endodontic regeneration (AL TAII et al, 2016 [58]), stem cell therapy in bone regeneration (SCHLIEPHAKE et al, 2001 [59]), implant studies (LANGHOFF et al, 2008 [60]).

The wide-scale use of sheep as an animal model in dental studies is due to several reasons. In addition to economic reasons - they are accessible, numerous and their breeding is of economic interest (DANESH-MEYER et al, 1997 [57]), there are many similarities of the anatomy of sheep teeth to human teeth, with an adequate growth rate, with the advantages and disadvantages of each dental age (AL TAII et al, 2016 [58]). The experimental sheep model uses the similarity to naturally occurring periodontal disease. Similarly to humans, individual variations in the extension and severity of the induced disease may complicate the interpretation of the healing response (DANESH-MEYER et al, 1997 [57]).

The main reason for using sheep is represented by periodontal disease in sheep which occurs naturally and is also termed "broken mouth" (BORSANELLI et al, 2017 [61]). Broken mouth periodontitis (BMP) is a painful disorder of sheep incisors, with many similarities to human CPD evolution: periodontal bacterial infection, formation of periodontal pockets, association of subgingival plaque with periodontal lesions (MCCOURTIE et al, 1990 [62]), severe degradation of periodontal collagen, chronic inflammation (gingivitis) with perivascular accumulation of mononuclear cells, plasma cells, lymphocytes and resorptive cells (osteoclasts and cementoclasts), high serum IgG levels, antibodies, significant alveolar bone resorption, epithelial inflammatory infiltration, gingival recession, degradation of blood capillary walls and bleeding on probing, increased tooth mobility and progressive tooth loss. It develops especially in sheep grazing in rough grasslands (ISMAIEL et al, 1989 [63]); (RIGGIO et al, 2013 [64]); (BORSANELLI et al, 2017 [61]). All these characteristics are similar to those found in rapidly destructive forms of human CPD (ISMAIEL et al, 1989 [63]).

Another important reason for using the sheep model is dental plaque which occurs naturally, including in the subgingival area. In this animal model, we succeeded in reproducing a larger amount of subgingival calculus, which is known to be a determining factor of risk for CPD onset (VAN DER VELDEN et al, 2006 [40]). Gingivitis is reversible, but in sensitive persons it progresses towards chronic periodontitis (KINANE et al, 2017 [3]). In sheep, broken mouth, which is natural and is a type of acute periodontitis with typical onset around a younger age, is a disease that is similar to human periodontitis in many regards (ISMAIEL et al, 1989 [63]).
We started in our study from the premise that it is preferable to choose sheep as a CPD model based on susceptibility to an acute form of gingival inflammation, which can more rapidly progress towards periodontitis. This premise is supported in humans by the study of Van der Velden et al, who indicate the fact that periodontal disease can develop at young ages, as well as an increase in susceptibility to CPD at the adult age (VAN DER VELDEN et al, 2006 [40]).

The bacterial composition of the oral flora and the development of dental plaque are also an important reason for choosing the sheep model of periodontal disease.

In human dental plaque, bacterial composition is influenced by many factors, including oxygen supply, $\mathrm{pH}$, diet, oral hygiene and intermicrobial interactions. Poor, insufficient oral hygiene or the lack of dental care, smoking, alteration of immunity, as well as other harmful factors might induce gingivitis (i.e. gingival tissue inflammation). Above and below the gingival margin, bacterial composition differs significantly. In healthy individuals, bacterial flora is mainly composed of aerobic streptococci, anaerobic actinomycetes and F. nucleatum (MOORE \& MOORE, 1994 [65]). It is known that the main bacterial species involved in human CPD are Porphyromonas gingivalis, Prevotella intermedia, Treponema denticola, Tannerella forsythia and Aggregatibacter actinomycetemcomitans (SANZ et al, 2018 [66]); (MOMBELLI, 2018 [67]); (YONG et al, 2015 [68]). Subgingival plaque (CHISTIAKOV et al, 2016 [6]) and the presence of Aggregatibacter actinomycetemcomitans (VAN DER VELDEN et al, 2006 [40]) play a major role in the development of gingivitis, as well as periodontitis. The oral flora in the sheep model has a distinct pattern and is associated with oral health and natural periodontitis (RIGGIO et al, 2013 [64]). A number of studies have reported similarities of the microflora and periodontitis between sheep and humans: species of Porphyromonas with black pigmentation (RIGGIO et al, 2013 [64]), Treponema (BORSANELLI et al, 2017 [61]), Bacteroides melaninogenicus/Prevotella (FRISKEN et al, 1989), (ISMAIEL et al, 1989 [63]), Bacteroides gingivalis (MCCOURTIE et al, 1990 [62]).

Even if an identical model of human periodontal disease has not yet been developed, bacterial colonization and the natural evolution of periodontal disease in sheep represent a valid argument to use the experimental sheep model of CPD.

\section{Conclusions}

Maintaining a healthy periodontal support has a positive impact on host immunity and can ensure prevention of other systemic inflammatory diseases.

Bacterial plaque control, removal of calculus and all local irritating factors that act on the marginal periodontium are essential in stopping gingivitis, periodontal attachment loss and finally tooth loss.

Dietary imbalances with decreased calcium absorption can favor periodontal disease. A diet poor in carbohydrates and rich in omega-3 fatty acids and vitamins $\mathrm{C}$ and $\mathrm{D}$ can significantly reduce gingival-periodontal inflammation.

The experimental sheep model of periodontal disease has many similarities to the human condition and could allow a more rapid study of therapeutic models.

Even if larger numbers of animals are required for a classification regarding physiological tooth mobility as well 
as physiological probing depth, natural periodontitis in sheep is an important argument to use sheep as an experimental model of chronic periodontitis.

Further studies with objective measurements of the serological markers of periodontal disease might be useful to confirm the importance of the animal model.

\section{Acknowledgements}

This article presents the partial results of the first author's doctoral thesis. The first author wishes to thank his colleagues at USAMV Cluj-Napoca for the logistic assistance provided.

$\mathrm{PhD}$ student Luca Vlad (Department of Propedeutics and Surgical Pathology), PhD student Coldea Răzvan (Department of Propedeutics and Surgical Pathology), PhD student Bogdan Sidonia (Department of Propedeutics and Surgical Pathology) and PhD student Filipaş Mălina (Department of Propedeutics and Surgical Pathology).

\section{References}

1. MOMEN-HERAVI F, BABIC A, TWOROGER SS, ZHANG L, WU K et al. (2017) Periodontal disease, tooth loss and colorectal cancer risk: Results from the Nurses' Health Study. International Journal of Cancer, 140, 646-652. DOI: $10.1002 /$ ijc.30486

2. HIGHFIELD J. (2009) Diagnosis and classification of periodontal disease. Australian Dental Journal, 54 Suppl 1, S11-S26. DOI: 10.1111/j.1834-7819.2009.01140.x

3. KINANE DF, STATHOPOULOU PG, PAPAPANOU PN. (2017) Periodontal diseases. Nature reviews. Disease primers, 3, 17038 DOI: 10.1038/nrdp.2017.38

4. NUVVULA S, CHAVA VK, NUVVULA S. (2016) Primary culprit for tooth loss!! Journal of Indian Society of Periodontology, 20, 222-224, DOI: 10.4103/0972124X.170852

5. MAWARDI HH, ELBADAWI LS, SONIS ST. (2015) Current understanding of the relationship between periodontal and systemic diseases. Saudi Medical Journal, 36, 150-158. DOI: 10.15537/smj.2015.2.9424

6. CHISTIAKOV DA, OREKHOV AN, BOBRYSHEV YV. (2016) Links between atherosclerotic and periodontal disease. Experimental and Molecular Pathology, 100, 220-235. DOI: 10.1016/j.yexmp.2016.01.006

7. CARRIZALES-SEPÚLVEDA EF, ORDAZ-FARÍAS A, VERA-PINEDA R, FLORES-RAMÍREZ R. (2018) Periodontal Disease, Systemic Inflammation and the Risk of Cardiovascular Disease. Heart, Lung and Circulation, 27, 1327-1334. DOI: 10.1016/j.hlc.2018.05.102

8. MARTIN-CABEZAS R, SEELAM N, PETIT C, AGOSSA K, GAERTNER S et al. (2016) Association between periodontitis and arterial hypertension: A systematic review and meta-analysis. American Heart Journal, 180, 98-112. DOI: 10.1016/j.ahj.2016.07.018

9. LAMSTER IB, PAGAN M. (2017) Periodontal disease and the metabolic syndrome. International Dental Journal, 67, 67-77. DOI: 10.1111/idj.12264

10. CARDOSO EM, REIS C, MANZANARES-CÉSPEDES MC. (2018) Chronic periodontitis, inflammatory cytokines, and interrelationship with other chronic diseases. Postgraduate Medicine, 130, 98-104. DOI: 10.1080/00325481.2018.1396876

11. HAJISHENGALLIS G. (2015) Periodontitis: from microbial immune subversion to systemic inflammation. Nature reviews. Immunology, 15, 30-44. DOI: 10.1038/ nri3785

12. SETE MR, FIGUEREDO CM, SZTAJNBOK F. (2016) Periodontitis and systemic lupus erythematosus. Revista Brasileira de Reumatologia, 56, 165-170. DOI: 10.1016/j.rbre.2015.09.001

13. COBB CM, KELLY PJ, WILLIAMS KB, BABBAR S, ANGOLKAR $M$ et al. (2017) The oral microbiome and adverse pregnancy outcomes. International Journal of Jomen's Health, 9, 551-559. DOI: 10.2147/IJWH. S142730

14. MICHAUD DS, FU Z, SHI J, CHUNG M. (2017) Periodontal Disease, Tooth Loss, and Cancer Risk. Epidemiologic reviews, 39, 49-58. DOI: 10.1093/epirev/ mxx006

15. RAMSEIER CA, ANERUD A, DULAC M, LULIC M, CULLINAN MP et al. (2017) Natural history of periodontitis: Disease progression and tooth loss over 40 years. Journal of Clinical Periodontology, 44, 11821191. DOI: $10.1111 /$ jcpe. 12782

16. PAPADOPOULOS G, KRAMER CD, SLOCUM CS, WEINBERG EO, HUA N et al. (2014) A mouse model for pathogen-induced chronic inflammation at local and systemic sites. Journal of Visualized Experiments, 90, e51556. DOI: $10.3791 / 51556$

17. HELIEH S OZ, DAVID A PULEO. Animal Models for Periodontal Disease, J Biomed Biotechnol, 2011, 754857 ,Affiliations Expand, PMID: 21331345, PMC3038839, DOI: $10.1155 / 2011 / 754857$

18. GRAVES DT, KANG J, ANDRIANKAJA O, WADA K, ROSSA C Jr. (2012) Animal models to study host-bacteria interactions involved in periodontitis. Frontiers of Oral Biology, 15, 117-132. DOI: 10.1159/000329675

19. HUJOEL PP, LINGSTRÖM P. (2017) Nutrition, dental caries and periodontal disease: a narrative review. Journal of Clinical Periodontology, 44 Suppl 18, S79S84. DOI: $10.1111 /$ jcpe. 12672

20. CHAPPLE IL, BOUCHARD P, CAGETTI MG, CAMPUS G, CARRA MC et al. (2017) Interaction of lifestyle, behaviour or systemic diseases with dental caries and periodontal diseases: consensus report of group 2 of the joint EFP/ORCA workshop on the boundaries between caries and periodontal diseases. Journal of Clinical Periodontology, 44 Suppl 18, S39-S51. DOI: $10.1111 /$ jcpe. 12685

21. VAN DER VELDEN U, KUZMANOVA D, CHAPPLE IL. (2011). Micronutritional approaches to periodontal therapy. Journal of Clinical Periodontology, 38 Suppl 11, 142-158. DOI: 10.1111/j.1600-051X.2010.01663.x

22. ZONG G, HOLTFRETER B, SCOTT AE, VÖLZKE H, PETERSMANN A et al. (2016) Serum vitamin B12 is inversely associated with periodontal progression and risk of tooth loss: a prospective cohort study. Journal of Clinical Periodontology, 43, 2-9. DOI: 10.1111/ jcpe. 12483

23. DOMMISCH H, KUZMANOVA D, JÖNSSON D, GRANT M, CHAPPLE I. (2018) Effect of micronutrient malnutrition on periodontal disease and periodontal 
therapy. Periodontology 2000, 78, 129-153. DOI: 10.1111/prd.12233

24. NAJEEB S, ZAFAR MS, KHURSHID Z, ZOHAIB S, ALMAS K. (2016) The Role of Nutrition in Periodontal Health: An Update. Nutrients, 8, 530. DOI: 10.3390/nu 8090530

25. TEOFIL L, MĂDĂLINA L. (2007) Parodontologie clinică, Editura Napoca Star, Cluj-Napoca, ISBN 978973-647-509-2, p.30-265

26. BODEA C, ENĂCHESCU G. (1984) Vegetables. In: Chemical composition of the main cultivated plants. Treatise of vegetal biochemistry. Part II, vol. V, $1^{\text {st }}$ Edit., Publishing House of the Academy of the Socialist Republic of Romania, Bucharest, 1984, pp. 191-194.

27. LI Z, HUANG H, ZHAO H, MENG K, ZHAO J et al. (2014) Genetic diversity and expression profiles of cysteine phytases in the sheep rumen during a feeding cycle. Letters in Applied Microbiology, 59, 615-620. DOI: 10.1111/lam.12318

28. NIEUW AMERONGEN AV, ODERKERK CH, VEERMAN EC. (1988) Influence of phytate on the adsorption of human salivary mucins onto hydroxyapatite. Journal de Biologie Buccale, 16, 203-208.

29. SILVA GA, MOREIRA A, ALVES JB. (2011) Histological processing of teeth and periodontal tissues for light microscopy analysis. Methods in Molecular Biology, 689, 19-36. DOI: 10.1007/978-1-60761-950-5_2

30. LIU H, ZHU R, LIU C, MA R, WANG L et al. (2017) Evaluation of Decalcification Techniques for Rat Femurs Using HE and Immunohistochemical Staining. BioMed Research International, 2017, 9050754. DOI: 10.1155/2017/9050754

31. FOSTER BL. (2012) Methods for studying tooth root cementum by light microscopy. International Journal of Oral Science, 4, 119-128. DOI: 10.1038/ijos.2012.57

32. BILGE FETTAHL OĞLU KARAMAN, ARBIL AÇIKALIN, İLKER ÜNAL, VAROL L AKSUNGUR. Int J Dermatol, 58 (3), 319-324 Mar 2019, Diagnostic Values of KOH Examination, Histological Examination, and Culture for Onychomycosis: A Latent Class Analysis, Affiliations Expand, PMID: 30246397, DOI: 10.1111/ijd.14255

33. WOODS GL, WALKER DH. Detection of infection or infectious agents by use of cytologic and histologic stains. Clin Microbiol Rev. 1996; 9(3): 382+404. PMID: 8809467 PMCID: PMC172900

34. STEFANOVIĆ D, SAMARDŽIJA G, REDŽEK A, ARNAUT M, NIKIN Z, \& STEFANOVIĆ, M. (2017). Buffered Romanowsky-Giemsa method for formalin fixed, paraffin embedded DOI: 10.1080/10520295.2017. 1315456

35. BUESA RJ. (2001). Giemsa Staining of Tissue Sections: A New Twist on an Old Technique. Journal of Histotechnology, 24(4), 251-253. doi:10.1179/his.2001. 24.4.251

36. COICO R. (2005). Gram Staining. Current Protocols in Microbiology, 2006; 00(1): A.3C.1-A.3C.2 DOI: 10.1002/9780471729259.mca03cs00

37. BECERRA SC, ROY DC, SANCHEZ CJ, CHRISTY RJ, BURMEISTER DM. An optimized staining technique for the detection of Gram positive and Gram negative bacteria within tissue. BMC Res Notes. 2016; 9: 216. DOI: 10.1186/s13104-016-1902-0

38. WANG Y, LIU G, LI T, XIAO Y, HAN Q, XU R, LI Y. Morphometric comparison of the lumbar cancellous bone of sheep, deer, and humans. PMCID:PMC2958206 [Indexed for MEDLINE] Comp Med. 2010 Oct; 60(5): 374-379.

39. SOARES HB, LAVINSKY L. Histology of sheep temporal bone. [Article in English, Portuguese] PMID: 21739000 [Indexed for MEDLINE] DOI: 10.1590/s180886942011000300003

40. VAN DER VELDEN U, ABBAS F, ARMAND S, LOOS BG, TIMMERMAN MF et al. (2006) Java project on periodontal diseases. The natural development of periodontitis: risk factors, risk predictors and risk determinants. Journal of Clinical Periodontology, 33, 540-548. DOI: 10.1111/j.1600-051X.2006.00953.X

41. CHU Y, OUYANG X. (2015) Accuracy of partial-mouth examination protocols for extent and severity estimates of periodontitis: a study in a Chinese population with chronic periodontitis. Journal of Periodontology, 86, 406-417. DOI: 10.1902/jop.2014.140422

42. PAYNE JB, NUMMIKOSKI PV, THOMPSON DM, GOLUB LM, STONER JA. (2013) The association between clinical and radiographic periodontitis measurements during periodontal maintenance. Journal of Periodontology, 84, 1382-1390. DOI: 10.1902/jop.2012.120484

43. SCHÄTZLE M, LOË H, LANG NP, BÜRGIN W, $\AA$ ANERUD $\AA$ et al. (2004) The clinical course of chronic periodontitis: IV. Gingival inflammation as a risk factor for tooth mortality. Journal of Clinical Periodontology, 31, 1122-1127 DOI: 10.1111/j.1600-051X.2004.00634.X

44. JONES DJ, MUNRO CL, GRAP MJ. (2011) Natural history of dental plaque accumulation in mechanically ventilated adults: a descriptive correlational study. Intensive and Critical Care Nursing, 27, 299-304. DOI: 10.1016/j.iccn.2011.08.005

45. VIELKIND P, JENTSCH H, ESCHRICH K, RODLOFF AC, STINGU CS. (2015) Prevalence of Actinomyces spp. in patients with chronic periodontitis. International Journal of Medical Microbiology, 305, 682-688. DOI: 10.1016/j.ijmm.2015.08.018

46. KOROSTOFF J, ARATSU A, KASTEN B, MUPPARAPU M. (2016) Radiologic Assessment of the Periodontal Patient. Dental Clinics of North America, 60, 91-104. DOI: 10.1016/j.cden.2015.08.003

47. ASLANI MR, MOVASSAGHI AR, NAJARNEZHAD V, PIROUZ HJ, BAMI MH. (2011) Acute oxalate intoxication associated to ingestion of eshnan (Seidlitzia rosmarinus) in sheep. Tropical Animal Health and Production, 43, 1065-1068. DOI: 10.1007/s11250-0119818-0

48. MUSHEGYAN V, ERONEN JT, LAWING AM, SHARIR A, JANIS C et al. (2015) Jernvall J, Klein OD. Continuously growing rodent molars result from a predictable quantitative evolutionary change over 50 million years. Cell Reports, 11, 673-680. DOI: 10.1016/j.celrep.2015.03.064

49. CHANDNA S, HEGDE S, BATHLA M. (2011) Animal models in Periodontology: a review. Journal of Oral Health Research, 2, 41-46. 
50. TYRRELL KL, CITRON DM, JENKINS JR, GOLDSTEIN EJ. (2002). Periodontal bacteria in rabbit mandibular and maxillary abscesses. Journal of Clinical Microbiology, 40, 1044-1047. DOI: 10.1128/jcm.40.3. 1044-1047.2002

51. HASTURK H, JONES VL, ANDRY C, KANTARCI A. (2007) 1-Tetradecanol complex reduces progression of Porphyromonas gingivalis-induced experimental periodontitis in rabbits. Journal of Periodontology, 78, 924-932. DOI: 10.1902/jop.2007.060293

52. OORTGIESEN DAW, MEIJER GJ, BRONCKERS ALJJ, WALBOOMERS XF, JANSEN JA. (2010). Fenestration defects in the rabbit jaw: an inadequate model for studying periodontal regeneration. Tissue Engineering, Part. C Methods, 16, 133-140. DOI: 10.1089/ten.TEC.2009.0191

53. ALBUQUERQUE C, MORINHA F, REQUICHA J, MARTINS T, DIAS I et al. (2012) Canine periodontitis: the dog as an important model for periodontal studies. Veterinary Journal, 191, 299-305. DOI: 10.1016/j. tvj1.2011.08.017

54. DANNAN A, ALKATTAN F. (2007) Animal Models in Periodontal Research: A Mini-Review of the Literature. The Internet Journal of Veterinary Medicine, 5, 1-9.

55. WANG S, LIU Y, FANG D, SHI S. (2007). The miniature pig: a useful large animal model for dental and orofacial research. Oral Diseases, 13, 530-537. DOI: 10.1111/ j.1601-0825.2006.01337.x

56. LIU Y, ZHENG Y, DING G, FANG D, ZHANG C et al. (2008) Periodontal Ligament Stem Cell-Mediated Treatment for Periodontitis in Miniature Swine. Stem Cells, 26, 1065-1073. DOI: 10.1634/stemcells.2007-0734

57. DANESH-MEYER MJ, PACK AR, MCMILLAN MD. (1997) A comparison of 2 polytetrafluoroethylene membranes in guided tissue regeneration in sheep. Journal of Periodontal Research, 32, 20-30. DOI: 10.1111/j.1600-0765.1997.tb01378.x

58. AL TAII M, BROBERG M, CATHRO P, RICHARDS L. (2016) Standardisation of sheep model for endodontic regeneration/revitalisation research. Archives of Oral Biology, 65, 87-94. DOI: 10.1016/j.archoralbio.2016. 01.008

59. SCHLIEPHAKE H, KNEBEL JW, AUFDERHEIDE M, TAUSCHER M. (2001) Use of cultivated osteoprogenitor cells to increase bone formation in segmental mandibular defects: an experimental pilot study in sheep. International Journal of Oral and Maxillofacial Surgery, 30, 531-537. DOI: 10.1054/ijom.2001.0164

60. LANGHOFF JD, VOELTER K, SCHARNWEBER D, SCHNABELRAUCH M, SCHLOTTIG F et al. (2008) Comparison of chemically and pharmaceutically modified titanium and zirconia implant surfaces in dentistry: a study in sheep. International Journal of Oral and Maxillofacial Surgery, 37, 1125-1132. DOI: 10.1016/j.ijom.2008.09.008
61. BORSANELLI AC, RAMOS TN, GAETTI-JARDIM E JR, SCHWEITZER CM, DUTRA IS. (2017) Treponema species in the subgingival microflora of ovine periodontitis. Veterinary Record, 180, 150. DOI: 10.1136/vr. 103946

62. MCCOURTIE J, POXTON IR, BROWN R, WHITTAKER CR, SPENCE JA et al. (1990). A longitudinal study of the cultivable subgingival anaerobic bacteria isolated from sheep during the development of broken mouth periodontitis. Journal of Medical Microbiology, 31, 275-283. DOI: 10.1099/00222615-31-4-275

63. ISMAIEL MO, GREENMAN J, MORGAN K, GLOVER MG, REES AS et al. (1989) Periodontitis in sheep: a model for human periodontal disease. Journal of Periodontology, 60, 279-284. DOI: 10.1902/jop.1989. 60.5.279

64. RIGGIO MP, JONSSON N, BENNETT D. (2013) Culture-independent identification of bacteria associated with ovine 'broken mouth' periodontitis. Veterinary Microbiology, 166, 664-669. DOI: 10.1016/j.vetmic. 2013.06.034

65. MOORE WEC, MOORE LVH. (1994) The bacteria of periodontal disease. Periodontology 2000, 5, 66-77. DOI: 10.1111/j.1600-0757.1994.tb00019.x

66. SANZ M, CERIELLO A, BUYSSCHAERT M, CHAPPLE I, DEMMER RT et al. (2018) Scientific evidence on the links between periodontal diseases and diabetes: Consensus report and guidelines of the joint workshop on periodontal diseases and diabetes by the International Diabetes Federation and the European Federation of Periodontology. Journal of Clinical Periodontology, 45, 138-149. doi: 10.1016/j.diabres. 2017.12.001.

67. MOMBELLI A. (2018) Microbial colonization of the periodontal pocket and its significance for periodontal therapy. Periodontology 2000, 76, 85-96. DOI: 10.1111/ prd.12147

68. YONG X, CHEN Y, TAO R, ZENG Q, LIU Z ET AL. (2015) Periodontopathogens and human $\beta$-defensin-2 expression in gingival crevicular fluid from patients with periodontal disease in Guangxi, China. Journal of Periodontal Research, 50, 403-410. DOI: 10.1111/ jre. 12220

69. RIGGIO MP, JONSSON N, BENNETT D. Blackpigmented Anaerobic Bacteria Associated With Ovine Periodontitis, Veterinary Microbiology 166 (2013), 664669 DOI: 10.1016/j.vetmic.2017.03.032.

70. ANA C BORSANELLI, ELERSON GAETTI-JARDIM JR, CHRISTIANE M SCHWEITZER, LORENZO VIORA, VALENTINA BUSIN, MARCELLO P RIGGIO, IVERALDO S DUTRA. Black-pigmented Anaerobic Bacteria Associated With Ovine Periodontitis, PMID: 28619155, DOI: 10.1016/j.vetmic .2017.03.032 